\title{
New functional nanocomposites based on poly(trimethylene 2,5-furanoate) and few layer graphene prepared by in situ polymerization
}

\author{
S. Paszkiewicz ${ }^{1 *}$, I. Janowska ${ }^{2}$, D. Pawlikowska ${ }^{1}$, A. Szymczyk ${ }^{3}$, I. Irska ${ }^{1}$, S. Lisiecki ${ }^{4}$, R. Stanik ${ }^{5}$ \\ M. Gude ${ }^{5}$, E. Piesowicz ${ }^{1}$ \\ ${ }^{1}$ West Pomeranian University of Technology, Institute of Material Science and Engineering, Piastow Av. 19, \\ 70310 Szczecin, Poland \\ ${ }^{2}$ Institute of Chemistry and Processes for Energy, Environment and Health (ICPEES), CNRS and University of \\ Strasbourg, 25 rue Becquerel, 67087 Strasbourg Cedex 2, France \\ ${ }^{3}$ West Pomeranian University of Technology, Institute of Physics, Piastow Av. 48, 70311 Szczecin, Poland \\ ${ }^{4}$ West Pomeranian University of Technology, Faculty of Food Sciences and Fisheries, Center of Bioimmoblisation and \\ Innovative Packaging Materials, Klemensa Janickiego str. 35, PL-71270 Szczecin, Poland \\ ${ }^{5}$ Technische Universität Dresden, Institute of Lightweight Engineering and Polymer Technology, Holbeinstraße 3, \\ 01307 Dresden, Germany
}

Received 6 December 2017; accepted in revised form 17 January 2018

\begin{abstract}
Poly(trimethylene 2,5-furanoate) (PTF) nanocomposites reinforced with few layer graphene (FLG) were prepared through in situ polymerization. The method in question allows obtaining well-dispersed nanoplatelets in the whole volume of PTF matrix. The mechanical properties of the PTF/FLG nanocomposites slightly increased with as quantity of FLG as small as $0.1 \mathrm{wt} \%$, which was best seen in the improvement of elongation at break by about two times. The presence of FLG did not affect the crystallization and chain mobility of PTF matrix. However, the incorporation of a small quantity of FLG slightly improved the thermal stability of the nanocomposites. Additionally, the cold and hot water absorption and oxygen permittivity measurements confirmed that FLG affected the tortuosity of the diffusive path for the penetrant molecule. Moreover, along with a successive addition of FLG a linear increase in thermal conductivity was visible.
\end{abstract}

Keywords: nanocomposites, biopolymers, thermal properties, mechanical properties, in situ polymerization

\section{Introduction}

The diminishing fossil fuel resources, along with fluctuating prices of crude oil, a significant greenhouse gas emissions and the limited biodegradability of (petroleum-derived) plastic materials involve a necessity of searching for renewable raw materials for their production [1-5]. Nearly $10 \%$ of extracted petroleum is used for the chemical industry. Any fluctuations associated with the extraction and price of this raw material are reflected in polymer industry situation, where alternatives are sought [4]. Renewable raw materials offer a wide range of chemical compounds that can replace previously used monomers or open the possibilities of the synthesis of new materials [2-6]. Renewable raw materials occupy the key position of plant biomass, which consists of, among others, lignin cellulose, starch, vegetable oils, vegetable proteins, aliphatic hydrocarbons, etc. Starch, the main component of cereals, is a biopolymer, which in the natural state or subjected to chemical modification can be used in the processing of synthetic materials. By using biochemical and/or chemical methods

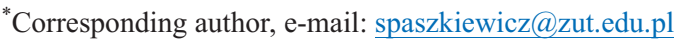
(C) BME-PT 
one can use the starch to obtain compounds that can replace the ingredients obtained from petrochemicals. These include, among others, 2,5-furanedicarboxylic acid (FDCA) synthesized from 5-hydroxymethylfurfural (HMF) [7]. It was identified as one of the twelve most promising compounds of vegetal origin for the synthesis of polymeric materials including polyurethanes, polyamides and polyesters $[2,4,5,8,9]$ as well as their copolymers with elastomeric properties. Polyesters that contain furan moieties in their structures, have been widely investigated for decades, starting with Moore and Kelly's pioneering research about thirty years ago [10] and continuing with some recent studies [7, 11-13]. Nevertheless, the synthesis of the furan homologue of poly (ethylene terephthalate) (PET), i.e. poly(ethylene 2,5-furandicarboxylate) (PEF), has not been reported in the last four decades. Novel approaches of the preparation of HMF lead in the large-scale production of FDCA [14] and thus enable to increase the production of polyesters bearing furan moieties like PEF [15], poly(butylene 2,5-furan dicarboxylate) (PBF) [16], that one can seriously regard as the biobased alternatives of terephthalates. Additionally, the successful production of PEF thin films and a comparison of the enzymatic hydrolysis of PEF and PET films have been reported by Weinberger et al. [17]. Similarly, one can find it for other thermoplastic polyesters, namely poly(trimethylene terephthalate) (PTT) and its furan homologue, i.e. poly(trimethylene 2,5furandicarboxylate) (PTF). PTF is a thermoplastic polyester, the synthesis of which has been reported just recently $[18,19]$. The molecular characterization and transition temperatures have been reported by Jiang et al. [19]. Still, the in-depth comparative study of a thermal behavior and solid state structure of PTF, in comparison to its terephthalate and naphthalate homologues, has been performed by Papageorgiou et al. [20]. However, there is no study on how the addition of carbon nanofillers, like graphene nanoplatelets, affect structural, thermal, mechanical etc. properties of PTF-based nanocomposites prepared by in situ polymerization.

One can find carbon nanofillers, like carbon nanotubes and graphene derivatives forms, very interesting due to their exceptional thermal, electrical and mechanical properties [21, 22]. Nowadays important efforts have been dedicated to find alternative routes for reducing the production's cost of such specific nanofillers and solve the processing conditions in order to achieve efficient dispersion (distribution) and orientation of such nanofillers within various polymer matrixes [22-24]. Commonly known, since 2004 'graphene', is a one-atom-thick planar layer of sp2 carbon atoms arranged in a honeycomb-type 2D lattice [25].This specific structure endows high quality graphene with remarkable properties such as high electron mobility at room temperature $\left(250000 \mathrm{~cm}^{2} /(\mathrm{V} \cdot \mathrm{s})\right)[26,27]$ and thus very high electrical conductivity and extremely low resistivity (theoretically of about $10^{-6} \Omega \cdot \mathrm{cm}$ ). It is flexible and it has exceptional thermal and mechanical properties with a thermal conductivity of about $5000 \mathrm{~W} \cdot \mathrm{m}^{-1} \cdot \mathrm{K}^{-1}$ [28], Young's modulus of $1 \mathrm{TPa}$ and ultimate strength of $130 \mathrm{GPa}$ [27]; moreover, its theoretical specific area exceeds $2500 \mathrm{~m}^{2} \cdot \mathrm{g}^{-1}[29,30]$. These extraordinary properties make graphene an exceptional material for many applications such as batteries, sensors, supercapacitors, solar cells, transistors, etc. [3133]. Graphene based materials are also very promising as fillers for making functional nanocomposites with various superior performances [34]. Apart from the monolayer graphene, the often so called graphene nanoplatelets filler include a few layer graphene (FLG), in which the number of sheets usually does not exceeds 10. The FLG with low sheets number permits to keep most of properties similar to graphene, while its preparation proceeds in general by relatively cost efficient and high yield top down method based on exfoliation methods $[35,36]$. Due to the above mentioned features of graphene nanoplatelets, their introduction into polymer matrices is found to lead to multifunctional nanocomposites with enhanced properties, while a good control of the interfacial interactions and their dispersion within the polymer matrix should be addressed. The final nanocomposite properties will depend also on the graphene platelet structure itself where not only number of the sheets and chemical composition but also the geometry and size of the platelets (and related aspect ratio) must be considered [37-39]. Started to be investigated much later, graphene-based polymer nanocomposites were yet definitely less studied when compared with the nanocomposites filled with carbon nanotubes or other nanofillers. It is especially wellseen in the polymer nanocomposites based on thermoplastic polyesters, like PET, PTT, PBT etc., which are engineering plastics with excellent processing characteristics and high strength and rigidity for a broad range of applications. Some studies on graphene 
nanoplatelets-polymer nanocomposites prepared by in situ polymerization, revealed significant improvements in electrical conductivity [40-44], thermal [45-47] and mechanical properties [42, 44, 46, 47], and gas barrier properties $[41,45]$. However, Lotti et al. [48] studied PEF nanocomposites containing $2.5 \mathrm{wt} \%$ of neat multi-walled carbon nanotubes (MWCNTs), or functionalized MWCNTs or graphene oxide (GO), that were in situ prepared by applying the melt polycondensation method. It was indicated that all nanofillers acted as nucleating agents for the PEF crystallization, but to a different extent. Indeed, the nanocomposites containing MWCNTs showed the highest melting temperature and the highest enthalpy of fusion among the tested nanocomposites.

The present study deals with the synthesis and characterization of PTF-based nanocomposites prepared by in situ polymerization method and containing FLG nanoplatelets (here called flakes) prepared by mechanical exfoliation method. All results are compared to the ones obtained for reference material, i.e. neat PTF. Mechanical, thermal and barrier properties, as well as thermal conductivity of the obtained nanocomposites are reported and discussed in terms of morphology and the state of dispersion and distribution of the FLG as assessed by spectroscopic and microscopic techniques.

\section{Experimental part}

\subsection{Materials}

The main materials used in this study were dimethyl furan 2,5-dicarboxylate with a purity of $99.9 \%$ (S2595, Sarchem Laboratories, Inc., Farmingdale, NJ, USA), Susterra ${ }^{\circledR} 1,3$-propanediol with purity of 99.6\% (bio-PDO ${ }^{\mathrm{TM}}$, DuPont Tate \& Lyle BioProducts, Loudon, USA), catalyst: tetrabutyl orthotitanate $\left(\mathrm{Ti}(\mathrm{OBu})_{4}\right.$, Fluka (distributor for Poland: Krakchemia S.A., Cracow, Poland) and antioxidant: Irganox 1010 (Ciba-Geigy, Basel, Switzerland).

Few layer graphene (FLG) was prepared by a modified method based on mechanical exfoliation (ablation) of graphite materials previously reported [49]. The modification of the method concerns initial graphite-based materials. Instead of the reported previously pencil lead, a pure graphite disc was exfoliated by mechanical ablation on the rough glass substrate using the set-up consisted of polishing-like apparatus, where horizontal macroscopic glass disc (30 $\mathrm{cm}$ in diameter) turned with controlled speed, while the graphite disc ablated over the glass surface was kept by suction cup system and hangs loose on the glass through a gravitation force. The ablated and attached to the glass surface material was systematically removed by ethanol to be finally recovered all and suspended in ethanol. The suspension was next submitted to a sedimentation process for four hours in order to separate heavier weakly exfoliated species. The supernatant containing FLG was then separated with an overall yield of around $60 \%$ and dried, first by the vacuum evaporation and eventually next in the standard oven at $100^{\circ} \mathrm{C}$ for $2 \mathrm{~h}$.

\subsection{Preparation of neat PTF and polymer nanocomposites}

Neat poly(trimethylene 2,5-furanoate) (PTF) and PTF-based nanocomposites were prepared via in situ polymerization, following the same procedure as described elsewhere for PTT based nanocomposites [41, 46, 50, 51]. In brief, 0.1 and $0.3 \mathrm{wt} \%$ of FLG was dispersed in $200 \mathrm{~mL}$ of bio-PDO using ultrahigh speed stirrer (Ultra-Turax T25, Wilmington, NC, USA) for $15 \mathrm{~min}$, and subsequently an ultrasonicator (Homogenizer HD 2200, Sonoplus (Berlin, Germany) with frequency of $20 \mathrm{kHz}$ and power $200 \mathrm{~W}$ ) for $15 \mathrm{~min}$. Then, the dispersion was subjected to weak ultrasounds in the ultra-power lower sonic bath (BANDELIN, Sonorex digitec (Berlin, Germany) with frequency of $35 \mathrm{kHz}$ and power $140 \mathrm{~W}$ ) for 8 hours. The prepared dispersion was added into the reaction mixture. The polymerization was performed in a 11 high pressure reactor (Autoclave Engineers Pennsylvania, USA) in two stages: transesterification under a constant flow of nitrogen in temperature range of $165-190^{\circ} \mathrm{C}$, in the presence of catalyst for about two hour. When the amount of by-product of this stage (methanol) was at about $90 \%$ of the stoichiometric calculated value, the second stage began. We have added the thermal stabilizer and second portion of catalyst along with the slow increase of the temperature up to $240^{\circ} \mathrm{C}$ and decrease the pressure (up to $20 \mathrm{~Pa}$ ). At this stage, the stirring torque change was monitored in order to estimate the melt viscosity of the product. Moreover, we have collected the effluent second by-product, i.e. 1,3-propylene glycol. All syntheses were finished when viscosity of the melt reached the same established value at $240^{\circ} \mathrm{C}$. The molten nanocomposite was extruded from the reactor into water bath, then granulated and dried before processing. The same conditions were applied to prepare the reference sample, i.e. the neat 
PTF. The dumbbell shape samples (type A3) for tensile and thermal conductivity measurements were obtained by injection moulding using Boy 15 (Dr BOY GmbH\&Co., Neustadt-Fernthal, Germany) injection moulding machine with the following parameters: injection pressure $55 \mathrm{MPa}$, melt temperature $240^{\circ} \mathrm{C}$, mould temperature $30^{\circ} \mathrm{C}$, holding down pressure of $20 \mathrm{MPa}$ for $15 \mathrm{~s}$ and cool time $10 \mathrm{~s}$.

\subsection{Thin films preparation}

Polymer/nanocomposites films with a thickness of $\approx 200 \pm 5 \mu \mathrm{m}$ were prepared for optical microscopy, conductivity and barrier studies by compression moulding (Collin P 200E) at $220^{\circ} \mathrm{C}$, and pressure of 5 bar for $2 \mathrm{~min}$ and 10 bar for another $1 \mathrm{~min}$ and subsequently quenched in cold water. The thickness of thin films was measured with a Micrometer mod. 293-521 from Mitutoyo. Five measurements were taken for each sample, with an experimental error of $\pm 0.001 \mathrm{~mm}$. The thickness is an average value.

\subsection{Characterization and measurements}

The dispersion of few layer graphene in the PTF matrix was observed by both scanning electron microscopy (SEM, JEOL JSM 6100, Freising, Germany) and transmission electron microscopy (TEM, JEOL 2100F, Freising, Germany). The samples for SEM analysis were cryofractured in liquid nitrogen and subsequently coated $(2-5 \mathrm{~nm})$ in vacuum with a thin gold film before the tests. Samples for TEM were also cryofractured in liquid nitrogen and deposited over gold grid. Moreover, light microscopy observations were performed for thin nanocomposites' films used for barrier and electrical measurements by using Nikon MM-40 microscope (Champaign, IL, USA) operating at transmission light mode.

The intrinsic viscosity $[\eta]$ of the samples was determined at the temperature of $30^{\circ} \mathrm{C}$ in the mixture of phenol/1,1,2,2-tetrachloroethane ( $60 / 40$ by weight) (Sigma-Aldrich). The polymer solution had a concentration of $0.5 \mathrm{~g} / \mathrm{dL}$. The measurement was carried on a capillary Ubbelohde viscometer (type Ic, $K=$ 0.03294).

The tensile properties of the prepared materials were measured using Autograph AG-X plus (Shimadzu, Duisburg, Germany) tensile testing machine equipped with a $1 \mathrm{kN}$ Shimadzu load cell, an non-contact optical extensometer and the TRAPEZIUM X computer software, operated at a constant crosshead speed of $5 \mathrm{~mm} / \mathrm{min}$. Measurements were performed at room temperature on the dumbbell samples with the grip distance of $20 \mathrm{~mm}$. According to PN-EN ISO 527 standard, the tensile modulus, yield stress and strain, stress and elongation at break of the nanocomposites were determined. Five measurements were conducted for each sample, and the results were averaged to obtain a mean value.

Water absorption tests were conducted in cold and boiling water in accordance with the test procedures recommended in ASTM D570. The dumbbell shape samples were dried to constant mass at $50^{\circ} \mathrm{C}$ within $24 \mathrm{~h}$, cooled to the room temperature and weighed. To measure the absorption of cold water all specimens were immersed in distilled water at $23{ }^{\circ} \mathrm{C}$ for $24 \mathrm{~h}$. Boiling water immersion was conducted for $30 \mathrm{~min}$, then specimens were allowed to cool down to room temperature in distilled water. The surface water was removed with filter paper. Then samples were weighed. Each reported value is an average of 5 test specimens.

The amorphous structure of the neat PTF and PTF based nanocomposites was confirmed by differential scanning calorimeter (DSC). Measurements were carried out with a DSC1 (Mettler Toledo, Leicester, UK) which was calibrated for the temperature and melting enthalpy by using indium and $n$-octane as a standards under a $\mathrm{N}_{2}$ atmosphere with a heating rate of $10 \mathrm{~K} / \mathrm{min}$ in the temperature range of $25-300^{\circ} \mathrm{C}$. Then, from the second heating the glass transition $T_{\mathrm{g}}$ and corresponding heat capacity were determined.

Thermo-oxidative stability of the obtained polymer/nanocomposites was performed by thermogravimetry (TGA 92-16.18 Setaram, Caluire-et-Cuire, France) using the system to measure the simultaneous TG-DTG. Measurements were carried out in an oxidizing atmosphere i.e. dry, synthetic air $\left(\mathrm{N}_{2}: \mathrm{O}_{2}=\right.$ 80:20 vol\%). The study was conducted in the temperature range of $20-700^{\circ} \mathrm{C}$ at the heating rate of $10^{\circ} \mathrm{C} / \mathrm{min}$. Measurements were performed in accordance with the PN-EN ISO 11358:2004 standard. In order to determine the thermal conductivity coefficient of the polymer/nanocomposite materials, the transient plane source (TPS) method, the Hot Disk TPS 2500 S (Uppsala, Sweden), and the Hot Disk thermal constants analyzer were used according to ISO 22007-2. The measurements were performed on the middle part of the sample sheet with the penetration depth of 3.5-3.9 $\mu \mathrm{m}$. All specimens with a thickness 
of approximately $2 \mathrm{~mm}$ were placed on both sides of the Hot Disk sensor touching the sensor with plane surfaces.

Oxygen permeability was measured using a MoconOx-Tran $2 / 10$ instrument $\left(23{ }^{\circ} \mathrm{C}\right.$ and $0 \%$ relative humidity (RH)) in accordance with ISO 15105-2 standard, while water vapor permeability was measured using a moisture analyzer (MAC 50, RADWAG, Poland) equipped with Sampler 2000, both using $5 \mathrm{~cm}^{2}$ samples of examined polymer films accordingly to the procedure previously described in detail in $[45,52]$. All polymer samples were conditioned for $3 \mathrm{~h}$ in the test chamber of OX-Tran apparatus in test parameters $\left(23^{\circ} \mathrm{C}\right.$ and $0 \%$ humidity rate $\left.\mathrm{RH}\right)$.

\section{Results and discussion}

\subsection{Dispersion of FLG}

FLG used in this study was prepared from graphite by mechanical ablation method as described above. Such prepared FLG flakes has in average 5-7 sheets and the lateral size of several $\mu \mathrm{ms}$ with the average one of around $5 \mu \mathrm{m}$. The planar geometry is weakly defined and mostly polygonal flakes are observed. Well-dispersed PTF/FLG nanocomposites were fabricated through a simple in situ polymerization method, preceded by an additional step of dispersing FLG (bio-PDO) using ultra-high speed stirrer and next an ultrasonicator, as described in the experimental section. The FLG contains some residual oxygencontaining functional groups (around $6 \%$ of oxygen) mostly from the edges and adsorbed ethanol residue and can be dispersed very well in liquid monomers (like ethylene or propylene glycol) at the level of individual flakes [40, 45, 52]. The dispersion state of FLG flakes in the PTF matrix was detected by scanning electron microscopy (SEM) and Figure 1a and $1 b$ show typical SEM images of the cross sections of the PTF/FLG nanocomposites with 0.1 and $0.3 \mathrm{wt} \%$ loading, respectively. The FLG flakes are clearly welldispersed in the PTF matrix and due to the residual oxygen-containing functional groups, they found to be 'anchored' to the matrix (Figure 1c and 1d). Transmission electron microscopy (TEM) was also employed to determine the existence of individual FLG flakes in PTF matrix. The TEM images shown in Figures $1 \mathrm{e}$ and $1 \mathrm{f}$ show that the graphite was successfully exfoliated into FLG flakes by mechanical exfoliation, and dispersed in the polymer molten state during the polymerization process. It can be seen from the TEM micrographs (Figurea 1e, 1f), that the number of sheets in FLG flakes is relatively weak, between 3 and 7. Moreover, the addition of FLG during the synthesis of PTF, was expected to play a critical role in obtaining truly homogenous co-dispersion of FLG at the macromolecular level.

\subsection{Mechanical properties and water absorption characteristics of PTF/FLG nanocomposites}

It was expected that the mechanical and water absorption performance of the PTF based nanocomposites would be significantly enhanced by the relatively large aspect ratio the FLG sheets (lateral size vs. thickness) [39] and the proper dispersion of the FLG sheets along with the interfacial interactions due to H-bonding between FLG and the in situ prepared PTF matrix. Table 1 presents the intrinsic viscosity values, the mechanical characteristic parameters, i.e. Young's modulus $(E)$, tensile strength and elongation at yield $\left(\sigma_{\mathrm{y}}, \varepsilon_{\mathrm{y}}\right)$ and strength and elongation at break $\left(\sigma_{\mathrm{b}}, \varepsilon_{\mathrm{b}}\right)$ and cold and hot water absorption performance. The addition of FLG caused no significant effect on the intrinsic viscosity values. There was only slight decrease in [ $\eta]$ for PTF/0.3 FLG nanocomposite, since the addition of higher content of FLG in the polymerization reaction, leading to the decrease of intrinsic viscosity. This observation is in agreement with our earlier studies on the PTT/expanded graphite nanocomposites [41]. The representative stress-strain relationship for PTF/FLG nanocomposites within the tested range of FLG weight concentrations is given in Figure 2. The mechanical performance of the PTF/0.1 FLG nanocomposite was slightly increased as compared to that of the neat PTF matrix (the Young's modulus increased from 5.43 to $5.64 \mathrm{GPa}$ ). Also the values of yield strength and strain initially slightly decreased to finally reach values like for neat PTF. However, at the same time, the stress at break decreased along with the increasing content of FLG in PTF matrix, of more than three times (from $84.07 \mathrm{MPa}$ for neat PTF to 61.74 MPa and 24.87 MPa for nanocomposites with 0.1 and $0.3 \mathrm{wt} \%$, respectively). Notwithstanding, the elongation at break of the nanocomposites was increased as compared to neat PTF (Figure 2, Table 1) almost six times. Because the aspect ratio and dispersion state of FLG were similar in nanocomposites with different FLG concentrations (Figure 1), the enhancement in mechanical properties (especially in the case of $\varepsilon_{\mathrm{b}}$ and $E$ ) are believed to arise from the 

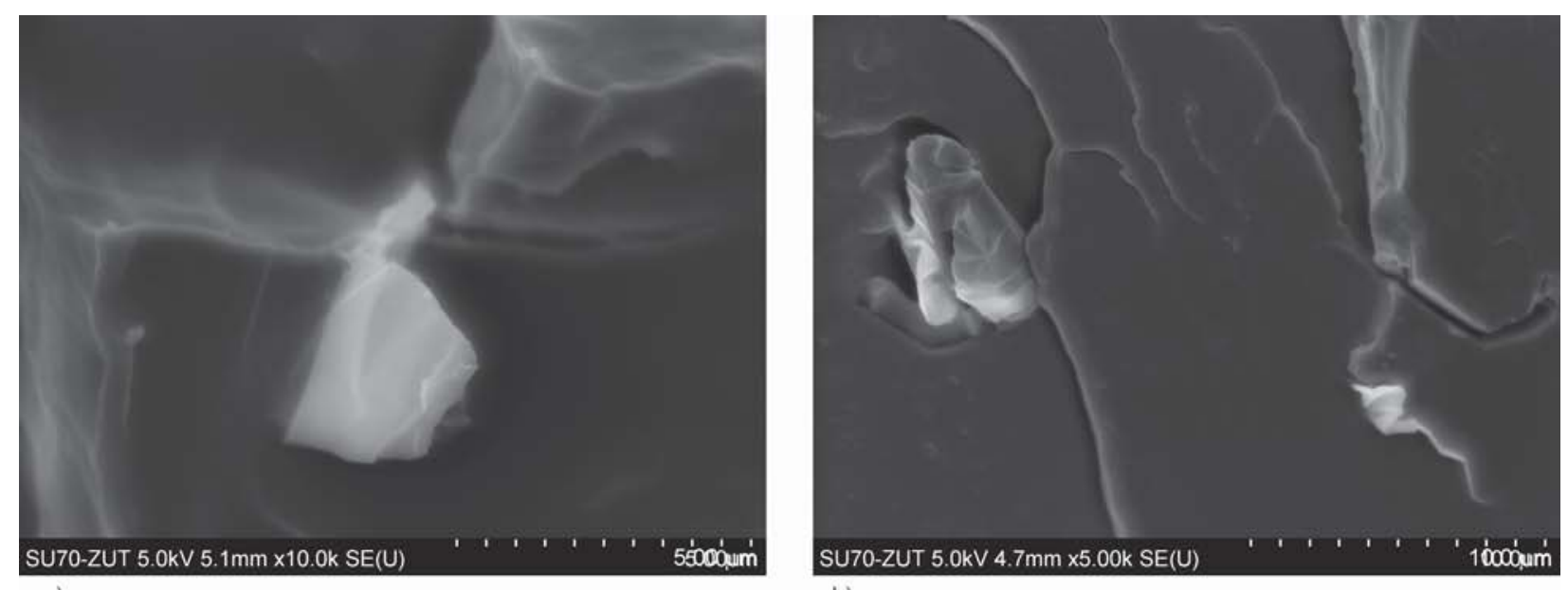

a)

\section{b)}

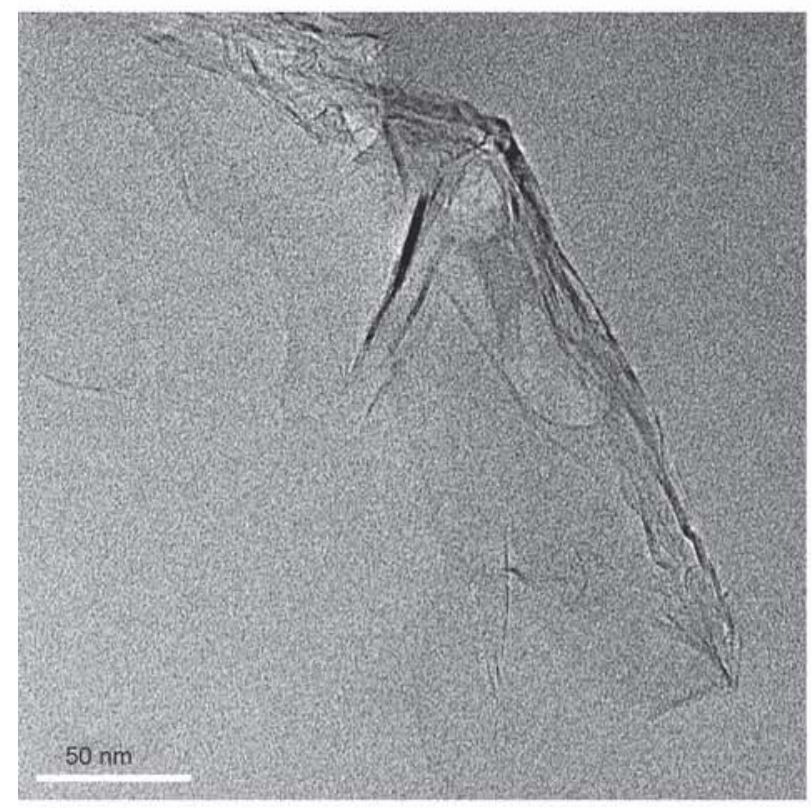

c)
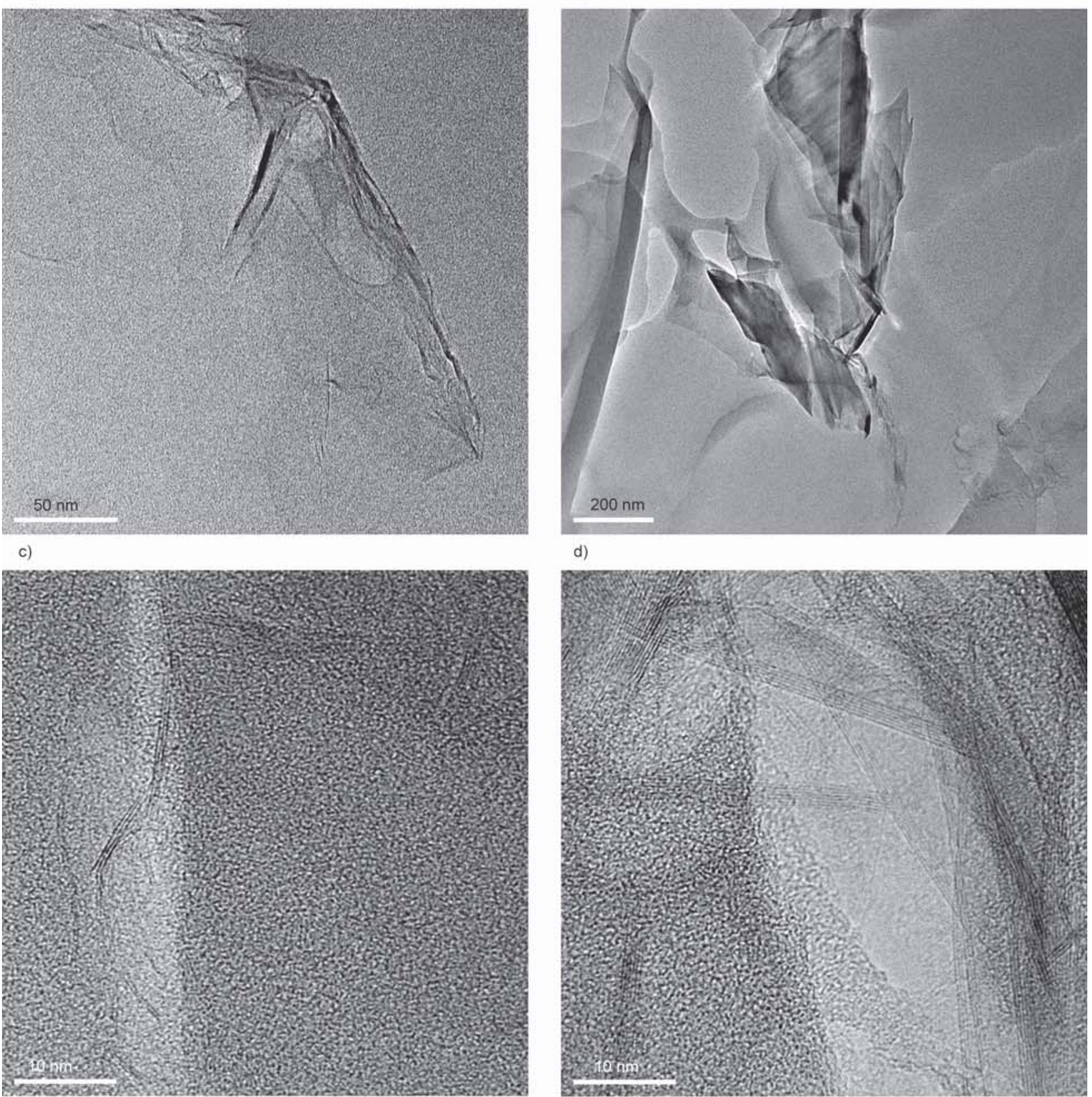

e)

\section{d)}

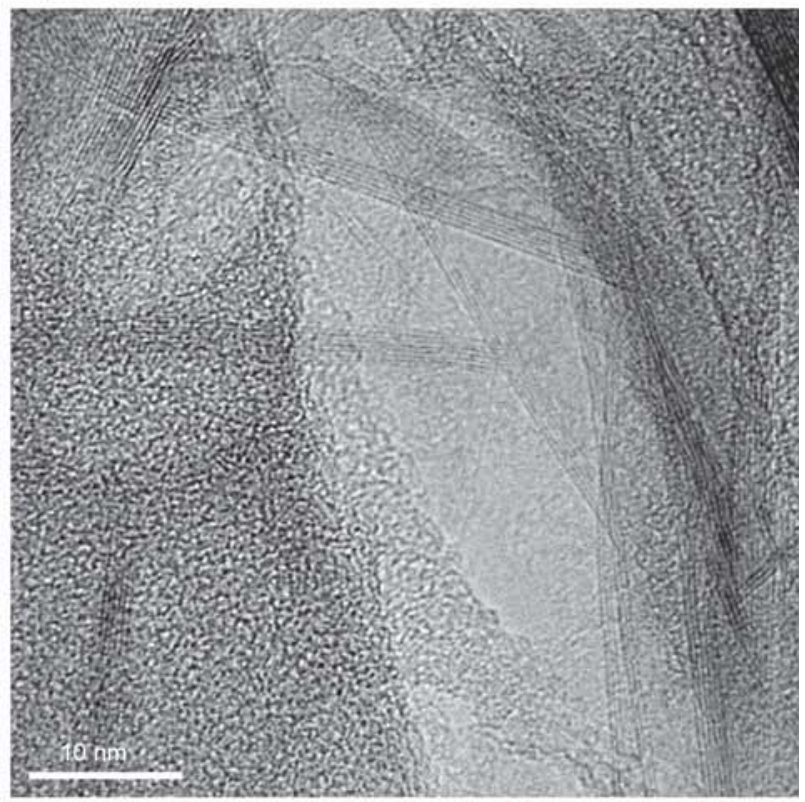

f)

Figure 1. SEM ( $a$ and $b$ ) and TEM ( $c$ to f) micrographs for the synthesised series of PTF-based nanocomposites containing: 0.1 FLG (a and e) and 0.3 FLG (b-d, f). 
Table 1. Intrinsic viscosity, tensile properties and cold and hot water absorption characteristics of PTF/FLG nanocomposites.

\begin{tabular}{|l|c|c|c|c|c|c|c|c|}
\hline \multicolumn{1}{|c|}{ Sample } & $\begin{array}{c}{[\boldsymbol{\eta}]} \\
{[\mathbf{d L} / \mathbf{g}]}\end{array}$ & $\begin{array}{c}\boldsymbol{E} \\
{[\mathbf{G P a}]}\end{array}$ & $\begin{array}{c}\mathbf{\sigma}_{\mathbf{y}} \\
{[\mathbf{M P a}]}\end{array}$ & $\begin{array}{c}\boldsymbol{\varepsilon}_{\mathbf{y}} \\
{[\mathbf{\%}]}\end{array}$ & $\begin{array}{c}\mathbf{\sigma}_{\mathbf{b}} \\
{[\mathbf{M P a}]}\end{array}$ & $\begin{array}{c}\boldsymbol{\varepsilon}_{\mathbf{b}} \\
{[\mathbf{\%}]}\end{array}$ & $\begin{array}{c}\mathbf{C W A} \\
{[\mathbf{\%}]}\end{array}$ & $\begin{array}{c}\text { HWA } \\
{[\%]}\end{array}$ \\
\hline $\mathrm{PTF}$ & 0.800 & $5.43 \pm 0.03$ & $48.69 \pm 3.03$ & $1.08 \pm 0.05$ & $84.070 \pm 4.43$ & $2.27 \pm 0.14$ & $0.20 \pm 0.02$ & $0.71 \pm 0.04$ \\
\hline $\mathrm{PTF} / 0.1 \mathrm{FLG}$ & 0.802 & $5.64 \pm 0.06$ & $40.23 \pm 1.33$ & $0.89 \pm 0.08$ & $61.740 \pm 5.66$ & $4.30 \pm 0.27$ & $0.18 \pm 0.01$ & $0.50 \pm 0.02$ \\
\hline PTF/0.3 FLG & 0.740 & $5.26 \pm 0.11$ & $48.09 \pm 3.31$ & $1.08 \pm 0.11$ & $24.871 \pm 3.86$ & $12.26 \pm 1.17$ & $0.10 \pm 0.01$ & $0.41 \pm 0.01$ \\
\hline
\end{tabular}

$[\eta]$ - intrinsic viscosity; $E$ - Young's modulus; $\sigma_{\mathrm{y}}-$ yield strength; $\varepsilon_{\mathrm{y}}-$ yield strain; $\sigma_{\mathrm{b}}, \varepsilon_{\mathrm{b}}-$ stress and strain at break respectively; CWA - cold water absorption; HWA - hot water absorption

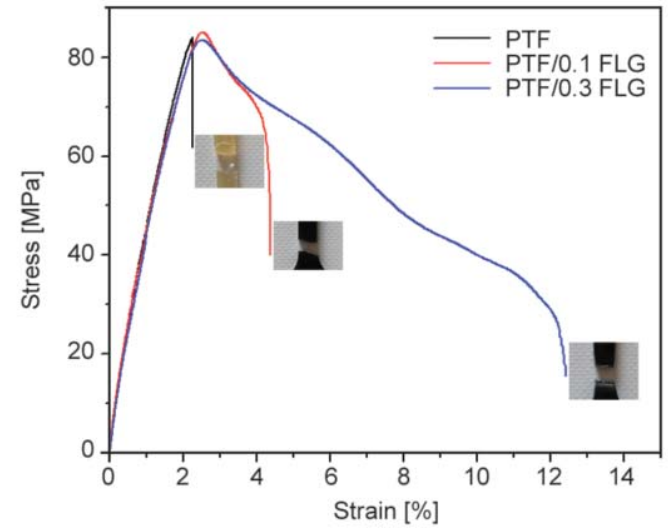

Figure 2. Representative stress-strain behavior for PTF/FLG nanocomposites with different FLG weight concentrations.

interactions between FLG and the PTF matrix. Probably, at still higher content of FLG in PTF matrix one can further observe the enhancement in mechanical performance, since the greatest improvement is observed at a concentration higher than $0.5 \mathrm{wt} \%$ [53-55].

Additionally, it was observed that the addition of FLG might affect the water absorption performance of PTF matrix. Along with an increase of FLG concentration from 0.1 to $0.3 \mathrm{wt} \%$ both, cold and hot water absorption were improved of about $100 \%$, which is due to the good distribution of highly hydrophobic FLG sheets in the matrix thereby reducing absorption in relation to water.

\subsection{Thermal characteristics of PTF/FLG nanocomposites}

Furanoate polyesters are an exceptional class of biobased polymers. In contrast to its terephthalate homologue (PTT), which exhibits semicrystalline behavior with melting temperature $\left(T_{\mathrm{m}}\right)$ at $\sim 228^{\circ} \mathrm{C}$ and crystallization temperature $\left(T_{\mathrm{c}}\right)$ at $\sim 183^{\circ} \mathrm{C}$ (heating and cooling rates of $10^{\circ} \mathrm{C} / \mathrm{min}$ ) [56], PTF at the same conditions found to be an amorphous thermoplastic polyester with no crystallization and melting temperatures (Figure 3). The glass transition temperature

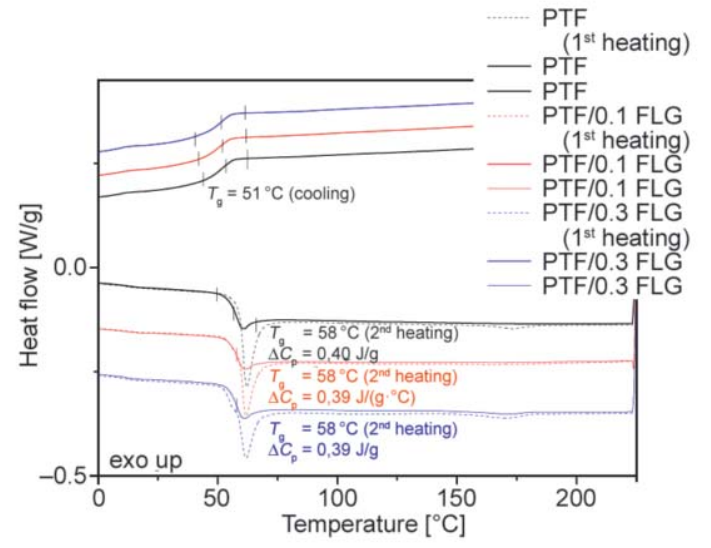

Figure 3. DSC thermograms during $1^{\text {st }}$ and $2^{\text {nd }}$ heating and cooling for PTF based nanocomposites containing FLG (drop line $1^{\text {st }}$ heating, continuous line $2^{\text {nd }}$ heating and cooling).

$\left(T_{\mathrm{g}}\right)$ for neat PTF is equal to $58^{\circ} \mathrm{C}$, which is slightly higher than that observed for melt quenched PTF by Papageorgiou et al. [20]. Notwithstanding, the incorporation of FLG into PTF matrix didn't cause any changes in the glass transition temperature. This is in agreement with our previous studies on the nanocomposites based on thermoplastic polyesters [41, 52, 57]. Furthermore, it was confirmed by the research of prof. Macosko's group, which showed that the $T_{\mathrm{g}}$ of polymer nanocomposites containing graphene can be increased only if strong interfacial interactions between polymers matrix and nanofillers occur [58, 59]. Since, there is no effect on the $T_{\mathrm{g}}$ values with the addition of FLG, one can say that the relaxation behavior of nanocomposite systems was not affected. A thermogravimetric analysis was performed on the nanocomposites in order to investigate the influence of FLG on the thermo-oxidative stability of the PTF matrix. The resulting curves are shown in Figure 4. The values of the temperatures corresponding to 5 , 25,50 and $90 \%$ mass loss as well as the temperatures at maximum of mass loss rate were determined from the curves and summarized in the Table 2 . The slight retardation of PTF decomposition was seen due to the presence of FLG. The retardation was probably 


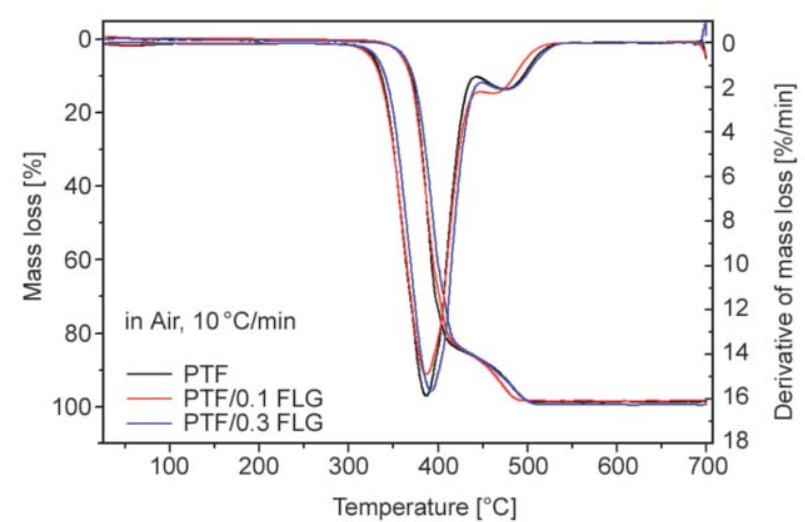

Figure 4. The mass loss and derivative of mass los curves of the PTF/FLG nanocomposites.

Table 2. Temperatures corresponding to 5, 25, 50 and $90 \%$ mass loss and the temperature at maximum of mass loss rate for the PTF/FLG nanocomposites obtained in an oxidizing atmosphere.

\begin{tabular}{|c|c|c|c|c|c|c|}
\hline Samples & $\begin{array}{l}T_{5 \%} \% \\
{\left[{ }^{\circ} \mathbf{C}\right]}\end{array}$ & $\begin{array}{l}\mathrm{T}_{25 \%} \\
{\left[{ }^{\circ} \mathrm{C}\right]}\end{array}$ & $\begin{array}{l}T_{50 \%} \% \\
{\left[{ }^{\circ} \mathbf{C}\right]}\end{array}$ & $\begin{array}{l}T_{90 \%} \% \\
{\left[{ }^{\circ} \mathbf{C}\right]}\end{array}$ & $\begin{array}{c}\text { DTG }_{1} \\
{\left[{ }^{\circ} \mathbf{C}\right]}\end{array}$ & $\begin{array}{c}\text { DTG }_{2} \\
{\left[{ }^{\circ} \mathbf{C}\right]}\end{array}$ \\
\hline PTF & 361 & 380 & 389 & 464 & 387 & 474 \\
\hline PTF/0.1 FLG & 360 & 379 & 390 & 458 & 387 & 462 \\
\hline PTF/0.3 FLG & 363 & 383 & 395 & 463 & 392 & 474 \\
\hline
\end{tabular}

the result of the adsorption by the FLG surface of the free radicals generated during PTF decomposition. The influence on the decomposition temperatures by the addition of FLG was comparable to those observed for PTT/EG $[41,46]$ at the same nanofiller contents, however the processing methods for obtaining FLG and EG, and the chemical morphology of PTT and PTF respectively are different.

Moreover, the outstanding thermal properties of graphene derivatives forms have been applied in order to improve not only the thermal and dimensional stability, but also the thermal conductivity of the host polymer. Pristine graphene exhibits high thermal conductivity due to the strong conjugated

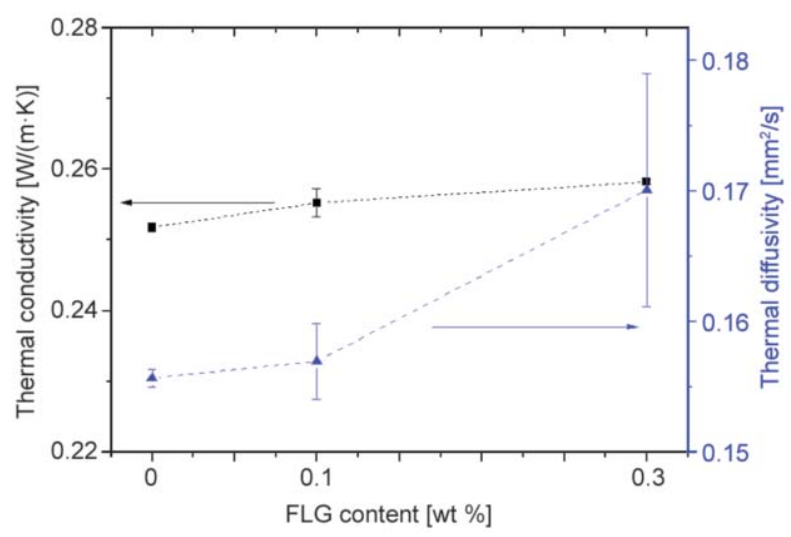

Figure 5. Thermal conductivity and thermal diffusivity of PTF/FLG nanocomposites as a function of FLG content.
$\mathrm{C}=\mathrm{C}$ covalent bonds and phonon scattering and is known for the highest thermal conductivity with room temperature value $\sim 3000 \mathrm{~W} \cdot \mathrm{m}^{-1} \cdot \mathrm{K}^{-1}$ in plane when suspended $[28,60]$ and approximately $600 \mathrm{~W} \cdot \mathrm{m}^{-1} \cdot \mathrm{K}^{-1}$

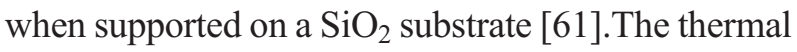
conductivity and thermal diffusivity vs. FLG content has been plotted in Figure 5. It was found that the addition of FLG flakes caused the enhancement in thermal conductivity of polymer matrix. Similarly, the enhancement in thermal diffusivity linearly increased along with an increasing content of nanosheets. The sheet-like geometry of graphene materials might provide lower interfacial thermal resistance and thus produce larger conductivity improvements in polymer composites [62]. Moreover, the geometry of graphene derivatives forms, aspect ratio, orientation and dispersion of graphene nanosheets may also affect thermal properties of composites. The linear increase in thermal conductivity and thermal diffusivity values are visible and confirm the observation from SEM/TEM analyses and mechanical tests about the relatively high aspect ratio and dispersion state of FLG.

\subsection{Thin polymer films}

The incorporation of graphene derivatives forms is expected to significantly affect the electrical conductivity and gas permeation through a polymer nanocomposites if compared to the neat polymer. A percolation network of graphene nanoplatelets can create both, electrical conducting paths, and the so-called 'tortuous paths' which inhibit molecular diffusion through the matrix, thus resulting in reducing its permeability. There are few studies where the addition of graphene derivatives species caused the improvement in electrical conductivity and barrier properties of thermoplastic polyesters. For instance, Zhang et al. [43] showed that the incorporation of graphene greatly improved the electrical conductivity of PET, resulting in a sharp transition from electrical insulator to semiconductor with a low percolation threshold of $0.47 \mathrm{vol} \%$. They also indicated the advantage of graphene nanosheets over graphite in enhancing properties of host polymer matrix. Additionally, Huang et al. [63], in PTT composites filled with well-dispersed graphene nanosheets (GNSs) prepared through a coagulation method, observed that electrical conductivity increased from $1.8 \cdot 10^{-17} \mathrm{~S} / \mathrm{cm}$ for neat PTT to $0.33 \pm 0.23 \mathrm{~S} / \mathrm{cm}$ for PTT/GNS composites with 2.97 vol\% GNS content. In turn, our previous 
studies on PTT based nanocomposites [41] proved that EG with the platelets size of $50 \mu \mathrm{m}$ enabled to obtain conductive thin polymer films with EG content of $0.3-0.5 \mathrm{wt} \%$, which also exhibited improvement in barrier properties with respect to $\mathrm{CO}_{2}$ and $\mathrm{O}_{2}$. In the present case the electrical conductivity was not achieved for $0.3 \%$ FLG as in the most results reported in the literature. The conductivity observed earlier the polymer donating expended graphite at this loading was mostly related to the extremely high lateral size of the EG flakes. Since, the proper dispersion state of FLG in the PTF matrix was achieved, one can conclude that at higher concentration of nanoplatelets an improvement in electrical conductivity will be observed. Moreover, the results of $\mathrm{O}_{2}$ transmission rate (OTR) trough neat PTF and PTF/ FLG nanocomposite films with comparable thickness of $200 \mu \mathrm{m}$ presented in Figure 6a complete the results of cold and hot water absorption measurements (Table 1). It is worth noting that PTF can be characterized by very low OTR values as compared to all these polymers, which are known for their good performances in packaging applications [64]. Previously, we found that the OTR value of PET equaled to $48.6 \pm 3.7 \mathrm{~cm}^{3} /\left(\mathrm{m}^{2} \cdot 24 \mathrm{~h}\right)$ [45]. However, Vannini et al. [64], showed that OTR values measured at $23{ }^{\circ} \mathrm{C}$ and $50 \%$ relative humidity were in the range of $0.0079-0.0472 \mathrm{~cm}^{3} \cdot \mathrm{cm} /\left(\mathrm{m}^{2} \cdot 24 \mathrm{~h} \cdot \mathrm{atm}\right) \mathrm{de}-$ pending on the aging time. Such improvement of barrier of furandicarboxylate (PTF) in comparison to terephthalate polyester (PET) is attributed to the higher rigidity of the furan rings. In fact, the phenyl ring-flipping mechanism present in PET is suppressed in the presence of furan ring, which causes a reduction of the segmental motions in PTF [64]. Moreover, one can attribute the mechanism for the improvement to the increase in the tortuosity of the diffusive paths for a penetrant molecule. As expected, the permeability of $\mathrm{O}_{2}$ through the PTF nanocomposite films was found considerably reduced for the highest concentration of FLG, i.e. $0.3 \mathrm{wt} \%$. The slight increase in OTR for PTF/0.1 FLG might result from the changes in viscosity (slight increase in intrinsic viscosity value, Table 1 ). Nevertheless, the improvement in impermeability in the case of PTF/0.3 FLG nanocomposite is due to relatively large and highly hydrophobic surface of FLG sheets, that inhibited the transport of oxygen molecules into and through the

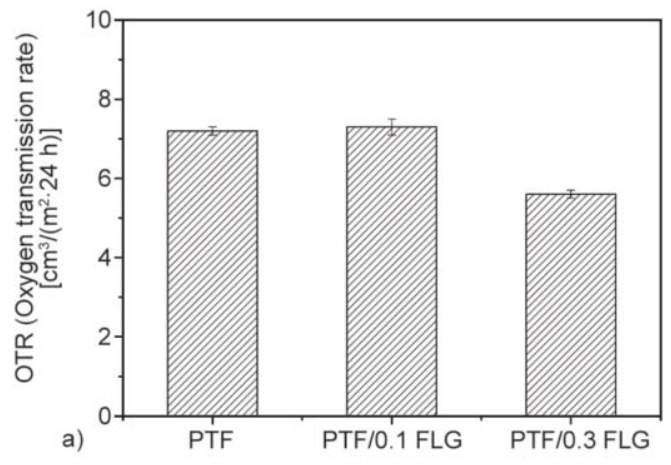

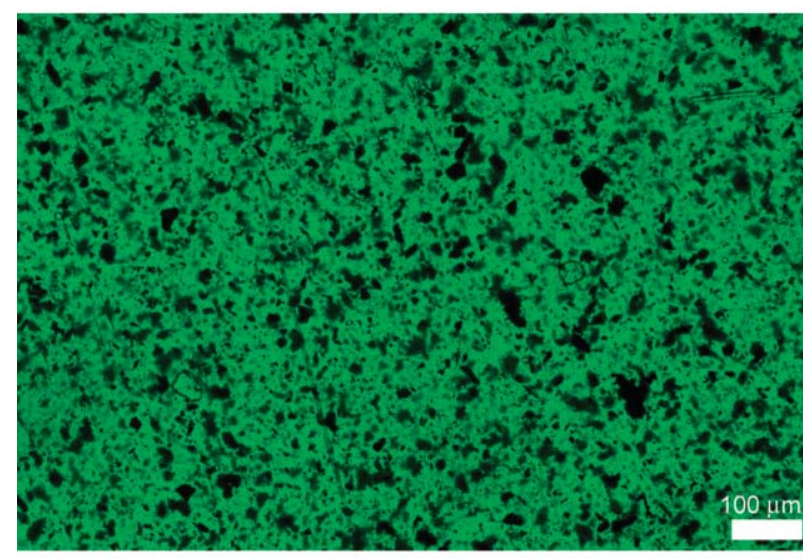

b)

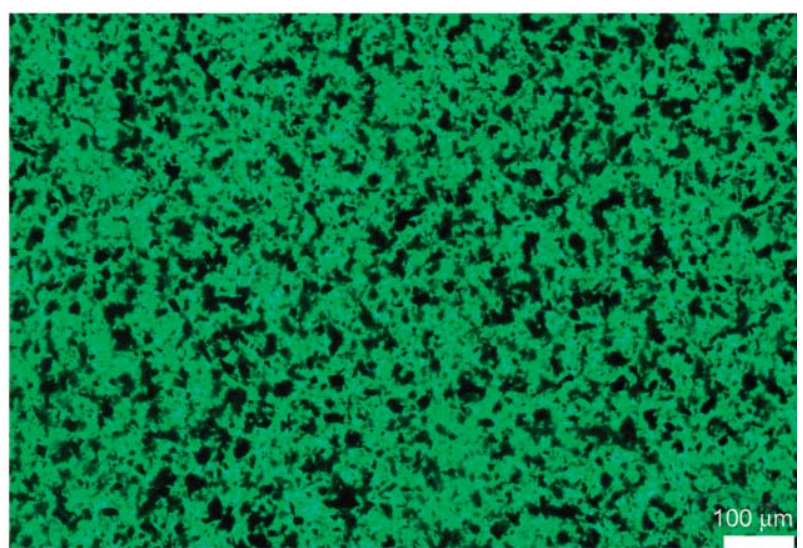

Figure 6. a) Oxygen permeability as a function of FLG content and b) and c) optical microscopy images of composites thin films used for dielectric and permeability measurements for nanocomposites containing 0.1 and $0.3 \mathrm{wt} \%$ of FLG, respectively. 
material, as well as to good distribution of FLG in the whole volume of PTF matrix (Figures $6 b$ and $6 c$ ). This is in agreement with our studies on PET based hybrid nanocomposites [65] and PET-G/graphene derivatives forms nanocomposites [52] prepared by in situ polymerization.

\section{Conclusions}

In situ polymerization method was used to prepare PTF nanocomposites filled with well-dispersed FLG, the latter prepared by high yield mechanical exfoliation. The method was effective, as indicated by both, scanning and transmission electron microscopies. A slight increase in Young's modulus (about 5\%) and $200 \%$ increase in elongation at break were achieved by addition of only $0.3 \mathrm{wt} \%$ of FLG. Regardless of FLG content, the glass transition temperature of the PTF matrix remained unchanged at $58^{\circ} \mathrm{C}$. Moreover, FLG didn't affect the melting/crystallization behavior of PTF matrix (no endo and exo-thermal peaks were seen in DSC thermograms during heating and cooling) and influenced the thermal stability of PTF matrix only in small manner. The concentration of $0.3 \mathrm{wt} \%$ didn't allow to obtain electrical conductive network, probably due to the insufficient aspect ratio of FLG, however a strong polymer-to-nanoplatelets interactions are reflected in improvement in thermal conductivity. Moreover, the improvement in cold and hot water absorption along with the decrease in OTR value suggest on relatively large and highly hydrophobic surface area of FLG planes, inhibiting the transport of oxygen molecules into and through the material. The above results confirmed the possible usage of $\mathrm{PTF} / \mathrm{FLG}$ nanocomposites in packaging application.

\section{Acknowledgements}

Authors would like to thank prof. Tiberio A. Ezquerra and $\mathrm{PhD}$ Amelia Linares from Instituto de Estructura de la Materia, IEM-CSIC(Madrid, Spain) for performing dielectric spectroscopy measurements. Izabela Janowska thanks to Dris Ihiawakrim from Institute of Physic and Chemistry of Materials of Strasbourg (IPCMS) for the TEM measurements.

\section{References}

[1] Reddy M. M., Vivekanandhan S., Misra M., Bhati S. K., Mohanty A. K.: Biobased plastics and bionanocomposites: Current status and future opportunities. Progress in Polymer Science, 38, 1653-1689 (2013).

https://doi.org/10.1016/j.progpolymsci.2013.05.006
[2] Bozell J. J., Petersen G. R.: Technology development for the production of biobased products from biorefinery carbohydrates - the US Department of Energy's 'Top 10' revisited. Green Chemistry, 12, 539-554 (2010). https://doi.org/10.1039/B922014C

[3] Muñoz-Guerra S., Lavilla C., Japu C., de Ilarduya A. M.: Renewable terephthalate polyesters from carbohydrate-based bicyclic monomers. Green Chemistry, 16, 1716-1739 (2014). https://doi.org/10.1039/C3GC42394H

[4] Ten E., Vermerris W.: Functionalized polymers from lignocellulosic biomass: State of the art. Polymers, 5, 600-642 (2013).

https://doi.org/10.3390/polym5020600

[5] Sousa A. F., Vilela C., Fonseca A. C., Matos M., Freire C. S. R., Gruter G-J. M., Coelho J. F. J., Silvestre A. J. D.: Biobased polyesters and other polymers from 2,5furandicarboxylic acid: A tribute to furan excellency. Polymer Chemistry, 6, 5961-5983 (2015).

https://doi.org/10.1039/C5PY00686D

[6] Kwiatkowska M., Kowalczyk I., Kwiatkowski K., Szymczyk A., Rosłaniec Z.: Fully biobased multiblock copolymers of furan-aromatic polyester and dimerized fatty acid: Synthesis and characterization. Polymers, 99, 503-512 (2016).

https://doi.org/10.1016/j.polymer.2016.07.060

[7] Papageorgiou G. Z., Papageorgiou D. G., Terzopoulou Z., Bikiaris D. N.: Production of bio-based 2,5-furan dicarboxylate polyesters: Recent progress and critical aspects in their synthesis and thermal properties. European Polymer Journal, 83, 202-229 (2016). https://doi.org/10.1016/j.eurpolymj.2016.08.004

[8] Pei L., Schmidt M., Wei W.: Conversion of biomass into bioplastics and their potential environmental impacts. in 'Biotechnology of Biopolymers' (ed.: Elnashar M.) InTech, Rijeka, 57-74 (2011). https://doi.org/10.5772/18042

[9] Zhang J., Li J., Tang Y., Lin L. Long M.: Advances in catalytic production of bio-based polyester monomer 2,5-furandicarboxylic acid derived from lignocellulosic biomass. Carbohydrate Polymers, 130, 420-428 (2015). https://doi.org/10.1016/j.carbpol.2015.05.028

[10] Moore J. A., Kelly J. E.: Polyesters derived from furan and tetrahydrofuran nuclei. Macromolecules, 11, 568573 (1978). https://doi.org/10.1021/ma60063a028

[11] Gandini A., Belgacem M. N.: Furans in polymer chemistry. Progress in Polymer Science, 22, 1203-1379 (1977). https://doi.org/10.1016/S0079-6700(97)00004-X

[12] Moreau C., Belgacem M. N., Gandini A.: Recent catalytic advances in the chemistry of substituted furans from carbohydrates and in the ensuing polymers. Topics in Catalysis, 27, 11-30 (2004). https://doi.org/10.1023/B:TOCA.0000013537.13540.0e 
[13] Gandini A., Belgacem M. N.: Furan derivatives and furan chemistry at the service of macromolecular materials. in 'Monomers, polymers and composites from renewable resources' (eds.: Belgacem M. N., Gandini A.,) Elsevier, Amsterdam, 115-152 (2008). https://doi.org/10.1016/B978-0-08-045316-3.00006-5

[14] Knoop R. J., Vogelzang W., van Haveren J., van Es D. S.: High molecular weight poly(ethylene-2,5-furanoate). Journal of Polymer Science Part A: Polymer Chemistry, 51, 4191-4199 (2013).

https://doi.org/10.1002/pola.26833

[15] Ma J., Pang Y., Wang M., Xu J., Ma H., Nie X.: The copolymerization reactivity of diols with 2,5 -furandicarboxylic acid for furan-based copolyester materials. Journal of Materials Chemistry, 22, 3457-3461 (2012). https://doi.org/10.1039/C2JM15457A

[16] Papageorgiou G. Z., Tsanaktsis V., Papageorgiou D. G., Exarhopoulos S., Papageorgiou M., Bikiaris D. N.: Evaluation of polyesters from renewable resources as alternatives to the current fossil-based polymers. Phase transitions of poly(butylene 2,5-furan-dicarboxylate). Polymer, 55, 3846-3858 (2014).

https://doi.org/10.1016/j.polymer.2014.06.025

[17] Weinberger S., Haernvall K., Scaini D., Ghazaryan G., Zumstein M. T., Sander M., Pellis A., Guebitz G. M.: Enzymatic surface hydrolysis of poly(ethylene furanoate) thin films of various crystallinities. Green Chemistry, 19, 5381-5384 (2017).

https://doi.org/10.1039/C7GC02905E

[18] Gomes M., Gandini A., Silvestre A. J., Reis B.: Synthesis and characterization of poly(2,5-furan dicarboxylate)s based on a variety of diols. Journalof Polymer Science Part A: Polymer Chemistry, 49, 3759-3768 (2011). https://doi.org/10.1002/pola.24812

[19] Jiang M., Liu Q., Zhang Q., Ye C., Zhou G.: A series of furan-aromatic polyesters synthesized via direct esterification method based on renewable resources. Journal of Polymer Science Part A: Polymer Chemistry, 50, 1026-1036 (2012).

https://doi.org/10.1002/pola.25859

[20] Papageorgiou G. Z., Papageorgiou D. G., Tsanaktsis V., Bikiaris D. N.: Synthesis of the bio-based polyester poly(propylene 2,5-furan dicarboxylate). Comparison of thermal behavior and solid state structure with its terephthalate and naphthalate homologues. Polymer, 62, 28-38 (2015).

https://doi.org/10.1016/j.polymer.2015.01.080

[21] Choi W., Lahiri I., Seelaboyina R., Kang Y. S.: Synthesis of graphene and its applications: A review. Critical Reviews in Solid State Materials Science, 35, 52-71 (2010).

https://oi.org/10.1080/10408430903505036

[22] Mittal G., Dhand V., Rhee K. Y., Park S-J., Lee W. R.: A review on carbon nanotubes and graphene as fillers in reinforced polymer nanocomposites. Journal of Industrial and Engineering Chemistry, 21, 11-25 (2015). https://doi.org/10.1016/j.jiec.2014.03.022
[23] Hu K., Kulkarni D. D., Choi I., Tsukruk V. V.: Graphenepolymer nanocomposites for structural and functional applications. Progress in Polymer Science, 39, 19341972 (2014).

https://doi.org/10.1016/j.progpolymsci.2014.03.001

[24] Moniruzzaman M., Winey K. I.: Polymer nanocomposites containing carbon nanotubes. Macromolecules, 39, 5194-5205 (2006).

https://doi.org/10.1021/ma060733p

[25] Kim H., Abdala A. A., Macosko C. W.: Graphene/polymer nanocomposites. Macromolecules, 43, 6515-6530 (2010). https://doi.org/10.1021/ma100572e

[26] Novoselov K. S., Geim A. K., Morozov S. V., Jiang D., Zhang Y., Dubonos S. V., Grigorieva I. V., Firsov A. A.: Electric field effect in atomically thin carbon films. Science, 306, 666-669 (2004).

https://doi.org/10.1126/science.1102896

[27] Lee C., Wei X., Kysar J. W., Hone J.: Measurement of the elastic properties and intrinsic strength of monolayer graphene. Science, 321, 385-388 (2008).

https://doi.org/10.1126/science.1157996

[28] Balandin A. A., Ghosh S., Bao W., Calizo I., Teweldebrhan D., Miao F., Lau C. N.: Superior thermal conductivity of single-layer graphene. Nano Letters, 8, 902907 (2008).

https://doi.org/10.1021/n10731872

[29] Bunch J. S., Verbridge S. S., Alden J. S., van der Zande A. M., Parpia J. M., Craighead H. G., McEuen P. L.: Impermeable atomic membranes from graphene sheets. Nano Letters, 8, 2458-2462 (2008).

https://doi.org/10.1021/n1801457b

[30] Viculis M. L., Mack J. J., Mayer O. M., Hahn H. T., Kaner R. B.: Intercalation and exfoliation routes to graphite nanoplatelets. Journal of Materials Chemistry, 15, 974-978 (2005).

https://doi.org/10.1039/B413029D

[31] Zhu Y., Murali S., Cai W., Li X., Suk J. W., Potts J. R., Ruoff R. S.: Graphene and graphene oxide: Synthesis, properties, and applications. Advanced Materials, 22, 3906-3924 (2010).

https://doi.org/10.1002/adma.201001068

[32] Avouris P., Xia F.: Graphene applications in electronics and photonics. MRS Bulletin, 37, 1225-1234 (2012). https://doi.org/10.1557/mrs.2012.206

[33] Huang L., Liang J., Chen Y.: An overview of the applications of graphene-based materials in supercapacitors. Small, 8, 1805-1834 (2012). https://doi.org/10.1002/smll.201102635

[34] Potts J. R., Dreyer D. R., Bielawski C. W., Ruoff R. S.: Graphene-based polymer nanocomposites. Polymer, 52, 5-25 (2011). https://doi.org/10.1016/j.polymer.2010.11.042

[35] Cai M., Thorpe D., Adamson D. H., Schniepp H. C.: Methods of graphite exfoliation. Journal of Materials Chemistry, 22, 24992-25002 (2012). https://doi.org/10.1039/C2JM34517J 
[36] Paredes J. I., Villar-Rodil S.: Biomolecule-assisted exfoliation and dispersion of graphene and other two-dimensional materials: A review of recent progress and applications. Nanoscale, 8, 15389-15413 (2016). https://doi.org/10.1039/C6NR02039A

[37] Vallés C., Abdelkader A. M., Young R. J., Kinloch I. A.: The effect of flake diameter on the reinforcement of few-layer graphene-PMMA composites. Composites Science and Technology, 111, 17-22 (2015). https://doi.org/10.1016/j.compscitech.2015.01.005

[38] Zhou T. N., Qi X. D., Fu Q.: The preparation of the poly(vinyl alcohol)/graphene nanocomposites with low percolation threshold and high electrical conductivity by using the large-area reduced graphene oxide sheets. Express Polymer Letters, 7, 747-755 (2013). https://doi.org/10.3144/expresspolymlett.2013.72

[39] Papagerogiou D. G., Kinloch I. A., Young R. J.: Mechanical properties of graphene and graphene-based nanocomposites. Progress in Materials Science, 90, 75127 (2017). https://doi.org/10.1016/j.pmatsci.2017.07.004

[40] Paszkiewicz S., Szymczyk A., Špitalský Z., Soccio M., Mosnáček J., Ezquerra T. A., Rosłaniec Z.: Electrical conductivity of poly(ethylene terephthalate)/expanded graphite nanocomposites prepared by in situ polymerization. Journal of Polymer Science Part B: Polymer Physics, 50, 1645-1652 (2012).

https://doi.org/10.1002/polb.23176

[41] Paszkiewicz S., Pawelec I., Szymczyk A., Špitalský Z., Mosnáček J., Kochmańska A., Rosłaniec Z.: Effect of exfoliated graphite nanoplatelets' size on the phase structure, electrical, and barrier properties of poly(trimethylene terephthalate)-based nanocomposites. Polymer Engineering and Science, 55, 2222-2230 (2015). https://doi.org/10.1002/pen.24107

[42] Li M., Jeong Y. G.: Poly(ethylene terephthalate)/exfoliated graphite nanocomposites with improved thermal stability, mechanical and electrical properties. Composites Part A: Applied Science and Manufacturing, 42, 560-566 (2011).

https://doi.org/10.1016/j.compositesa.2011.01.015

[43] Zhang H-B., Zheng W-G., Yan Q., Yang Y., Wang J-W., Lu Z-H., Ji G-Y., Yu Z-Z.: Electrically conductive polyethylene terephthalate/graphene nanocomposites prepared by melt compounding. Polymer, 51, 1191-1196 (2010).

https://doi.org/10.1016/j.polymer.2010.01.027

[44] Zhang M., Li D-Y., Wu C-H., Yan V-H., Lu P., Qiu G-M.: Poly(ethylene terephthalate)/expanded graphite conductive composites: Structure, properties, and transport behavior. Journal of Applied Polymer Science, 180, 1482-1489 (2008).

https://doi.org/10.1002/app.27745
[45] Szymczyk A., Paszkiewicz S., Pawelec I., Lisiecki S., Jotko M., Špitalský Z., Mosnáček J., Rosłaniec Z.: Oxygen barrier properties and melt crystallization behavior of poly(ethylene terephthalate)/graphene oxide nanocomposites. Journal of Nanomaterials, 2015, 382610/1382610/10 (2015).

https://doi.org/10.1155/2015/382610

[46] Paszkiewicz S., Pawelec I., Szymczyk A., Rosłaniec Z.: Mechanical and thermal properties of hybrid nanocomposites prepared by in situ polymerization. Polimery, 61, 172-180 (2016).

https://doi.org/10.14314/polimery.2016.172

[47] Fabbri P., Bassoli E., Bon S. B., Valentini L.: Preparation and characterization of poly (butylene terephthalate)/ graphene composites by in-situ polymerization of cyclic butylene terephthalate. Polymer, 53, 897-902 (2012). https://doi.org/10.1016/j.polymer.2012.01.015

[48] Lotti N., Munari A., Gigli M., Gazzano M., Tsanaktsis V., Bikiaris D. N., Papageorgiou G. Z.: Thermal and structural response of in situ prepared biobased poly(ethylene 2,5-furan dicarboxylate) nanocomposites. Polymer, 103, 288-298 (2016).

https://doi.org/10.1016/j.polymer.2016.09.050

[49] Janowska I., Vigneron F., Bégin D., Ersen O., Bernhardt P., Romero T., Ledoux M. J., Pham-Huu C.: Mechanical thinning to make few-layer graphene from pencil lead. Carbon, 50, 3106-3110 (2012). https://doi.org/10.1016/j.carbon.2012.02.064

[50] Paszkiewicz S., Szymczyk A., Sui X. M., Wagner H. D., Linares A., Cirera A., Varea A., Ezquerra T. A., Rosłaniec Z.: Electrical conductivity and transparency of polymer hybrid nanocomposites based on poly(trimethylene terephthalate) containing single walled carbon nanotubes and expanded graphite. Journal of Applied Polymer Science, 134, 44370/1-44370/9 (2017). https://doi.org/10.1002/app.44370

[51] Paszkiewicz S., Szymczyk A., Janowska J., Jedrzejewski R., Linares A., Ezquerra T. A., Wagner H. D., Tenne R., Rosłaniec Z.: Comparative study on the properties of poly(trimethylene terephthalate)-based nanocomposites containing multi-walled carbon (MWCNT) and tungsten disulfide (INT-WS2) nanotubes. Polymers of Advanced Technologies, 28, 654-657 (2017). https://doi.org/10.1002/pat.3964

[52] Paszkiewicz S., Szymczyk A., Pawlikowska D., Irska I., Piesowicz E., Jotko M., Lisiecki S., Bartkowiak A., Sieradzka M., Fryczkowski R., Kochmanska A., Kochmanski P., Rosłaniec Z.: Improvement of barrier properties of glycol modified poly(ethylene terephthalate) based nanocomposites containing graphene derivatives forms. Polimery, 62, 868-874 (2017). https://doi.org/10.14314/polimery.2017.868 
[53] Liang J., Huang Y., Zhang L., Wang Y., Ma Y., Guo T., Chen Y.: Molecular-level dispersion of graphene into poly(vinyl alcohol) and effective reinforcement of their nanocomposites. Advanced Functional Materials, 19, 2297-2302 (2009).

https://doi.org/10.1002/adfm.200801776

[54] Song P., Cao Z., Cai Y., Zhao L., Fang Z., Fu S.: Fabrication of exfoliated graphene-based polypropylene nanocomposites with enhanced mechanical and thermal properties. Polymer, 52, 4001-4010 (2001). https://doi.org/10.1016/j.polymer.2011.06.045

[55] Fang M., Wang K., Lu H., Yang H., Nutt S.: Covalent polymer functionalization of graphene nanosheets and mechanical properties of composites. Journal of Materials Chemistry, 19, 7098-7105 (2009).

https://doi.org/10.1039/B908220D

[56] Huang J-M., Ju M-Y., Chu P. P., Chang F-C.: Crystallization and melting behaviors of poly(trimethylene terephthalate). Journal of Polymer Research, 6, 259266 (1999).

https://doi.org/10.1007/s10965-006-0096-x

[57] Paszkiewicz S., Szymczyk A., Špitalský Z., Mosnáček J., Janus E., Rosłaniec Z.: Effect of addition of expanded graphite (EG) on the synthesis and characteristics of poly(ethylene terephthalate) modified with cyclohexanedimethanol (PETG). Polimery, 58, 893-899 (2013). https://doi.org/10.14314/polimery.2013.893

[58] Macosko C. W.: Does graphene change $T_{\mathrm{g}}$ of nanocomposites? in 'Proceedings of international conference on carbon nano particle based composites. Dresden, Germany' 22-23 (2013).

[59] Liao K-H., Aoyama S., Abdala A. A., Macosko C. W.: Does graphene change $T_{\mathrm{g}}$ of nanocomposites? Macromolecules, 47, 8311-8319 (2014).

https://oi.org/10.1021/ma501799z
[60] Ghosh S., Calizo I., Teweldebrhan D., Pokatilov E. P., Nika D. L., Balandin A. A., Bao W., Miao F., Lau C. N.: Extremely high thermal conductivity of graphene: Prospects for thermal management applications in nanoelectronic circuits. Applied Physics Letters, 92, 151911/1-151911/3 (2008).

https://doi.org/10.1063/1.2907977

[61] Seol J. H., Jo I., Moore A. L., Lindsay L., Aitken Z. H., Pettes M. T., Li X., Yao Z., Huang R., Broido D., Mingo N., Ruoff R. S., Shi L.: Two-dimensional phonon transport in supported graphene. Science, 328, 213-216 (2010).

https://doi.org/10.1126/science.1184014

[62] Lin W., Zhang R., Wong C. P.: Modeling of thermal conductivity of graphite nanosheet composites. Journal of Electronic Materials, 39, 268-272 (2010). https://doi.org/10.1007/s11664-009-1062-2

[63] Huang C-L., Wang Y-J., Fan Y-C.: Morphological features and crystallization behavior of the conductive composites of poly(trimethylene terephthalate)/graphene nanosheets. Journal of Applied Polymer Science, 133, 43419/1-43419/14 (2016).

https://doi.or/10.1002/app.43419

[64] Vannini M., Marchese P., Celli A., Lorenzetti C.: Fully biobased poly(propylene 2,5-furandicarboxylate) for packaging applications: Excellent barrier properties as a function of crystallinity. Green Chemistry, 17, 41624166 (2015). https://doi.org/10.1039/C5GC00991J

[65] Paszkiewicz S., Kwiatkowska M., Rosłaniec Z., Szymczyk A., Jotko M., Lisiecki S.: The influence of different shaped nanofillers (1D, 2D) on barrier and mechanical properties of polymer hybrid nanocomposites based on PET prepared by in situ polymerization. Polymer Composites, 37, 1949-1959 (2016).

https://doi.org/10.1002/pc.23373 